\title{
XXV Triennial World Congress - SICOT 2011
}

\author{
Maurice Hinsenkamp
}

Published online: 16 June 2011

(C) Springer-Verlag 2011

The Triennial World Congress in Prague in parallel with the exceptional evolution of our journal International Orthopaedics provides a very good image of the current expansion of SICOT by the quality of the scientific presentations and by the international representation in the different fields of orthopaedic surgery and traumatology. It reflects all the advantages of a global orthopaedic society. From 6 to 9 September 2011, you will be able to select your menu "à la carte" from 12 parallel sessions handled by the most renowned specialists in the world.

The Congress will include five plenary conferences, 239 invited speakers, 11 symposia and 83 sessions devoted to free oral presentations to allow the active participation of a maximum number of participants. This year we inaugurate e-posters augmented by specific short oral presentations of a selection of them during focus poster sessions.

As education represents a significant part of the objectives of SICOT, 18 instructional courses on the main topics and one educational day on the hip are scheduled. Instructional courses set out to cover exhaustively specific topics mostly aimed at young colleagues, and some will include hands-on demonstrations. The main subjects are: TKR balancing, revision of total knee arthroplasty, guided TKA: is it worth it?, lengthening of long bones, surgical management of spinal deformities, damage control in poly-traumatised patients, reverse shoulder arthroplasty, management of rotator cuff pathology, musculoskeletal tumours in children, distal radial fractures including a hands-on course, natural disasters

M. Hinsenkamp $(\bowtie)$

Service d'Orthopédie Traumatologie, Hôpital Erasme, Brussels, Belgium

e-mail: Maurice.Hinsenkamp@erasme.ulb.ac.be and mass casualties, DVT prevention in orthopaedics and current management of osteoporosis.

More specialised symposia give the present state of the art in other specific fields. This year, they will focus on high tibial osteotomy, cartilage repair, hip arthroscopy, modular stem prostheses of the hip, TB spine, ultrasound in orthopaedics and how to write and publish a paper, presented by the Editors of the main orthopaedic journals including International Orthopaedics.

Trauma will be an important part of the meeting. The SICOT Trauma Committee, chaired by Vilmos Vécsei, will focus on fractures around the knee with one symposium and three free paper sessions on the subject. Controversial topics are also covered. To keep pace with the current tragic events in the world, a symposium on natural disasters will attempt to help the humanitarian volunteers in their assessment of the indications for amputation which always remains a difficult decision for the surgeon. The spine has received special attention with the support of our SICOT President Cody Bünger together with an open session of the Scoliosis Research Society.

The different disciplines are highlighted by ten specialty societies' sessions and symposia including the International Hip Society, Association for the Rational Treatment of Fractures (ARTOF), Computer Assisted Orthopaedic Surgery (CAOS), International Society for Minimal Intervention in Spine Surgery (ISMISS), European Society of Sport Traumatology, Knee Surgery and Arthroscopy and many others.

Paediatric orthopaedics will be represented, as is now a tradition, by the International Federation of Paediatric Orthopaedic Societies (IFPOS) and the International Club Foot study group. A symposium on paediatric trauma and an instructional course on the Ponseti management of the club foot will complete the information. 
The industry is extensively represented with a large technical exhibition and special courses to be held during the lunch workshops.

The SICOT head office has worked very hard together with the local organising committee to develop this exceptional programme. We thank Thomas Trç, the Congress President and Votech Havlas, the Local Scientific Chair, for their involvement and their arrangement of a series of memorable and attractive social events to complement the scientific programme.

As the Czech Republic is our guest, I should honour, among others, such great national orthopaedic surgeons as Prof. Jan Zahradnicek and his work on congenital hip dysplasia who was a founding member of SICOT in 1929 and was followed by Oldrich Cech, his last pupil and National Delegate of SICOT from 1990 to 2000. He was also for many years the Editor in Chief of the Acta Chirurgiae Orthopaedicae et Traumatologiae Cechoslovaca.

The SICOT Congress and our journal International Orthopaedics with their contribution at the sharp edge of scientific knowledge offer many countries a unique international forum to exchange and discuss their scientific contribution at the highest scientific level.

Be part of these world events in orthopaedic surgery and traumatology. 